\title{
Sending data from excel to autocad
}

\author{
Alexandru BABA $\breve{A}^{*}$ \\ University of Pitești, Romania \\ *Corresponding author e-mail: $\underline{\text { sandubaba59@yahoo.com }}$ \\ Article history \\ Received 12.07.2020 \\ Accepted $\quad 12.09 .2020$ \\ DOI https://doi.org/10.26825/bup.ar.2020.003
}

\begin{abstract}
The interaction between Excel and AutoCad using VBA is useful for all engineers who use AutoCad, so in this article I want to show that using VBA in Excel can draw objects in AutoCad. Therefore, by programming in VBA from Excel, you can launch AutoCAD and with the help of a spreadsheet application we transmit the data in AutoCAD to draw objects.
\end{abstract}

Keywords: VBA Excel, Autocad, Excel and Autocad, VBA Excel Documentation, Link Excel to Autocad using VBA

\section{Introduction}

In the design activity, engineers using Autocad must integrate the power of Microsoft Excel through a programming concept necessary for connecting and exchanging data between the two products through VBA Excel or VBA Autocad.

To connect Excel to Autocad we must first launch Excel, then VBA Excel and from Tools / References select Autocad objects to use together with their properties in our VBA code.

The following code is also used to open Autocad using Excel VBA:

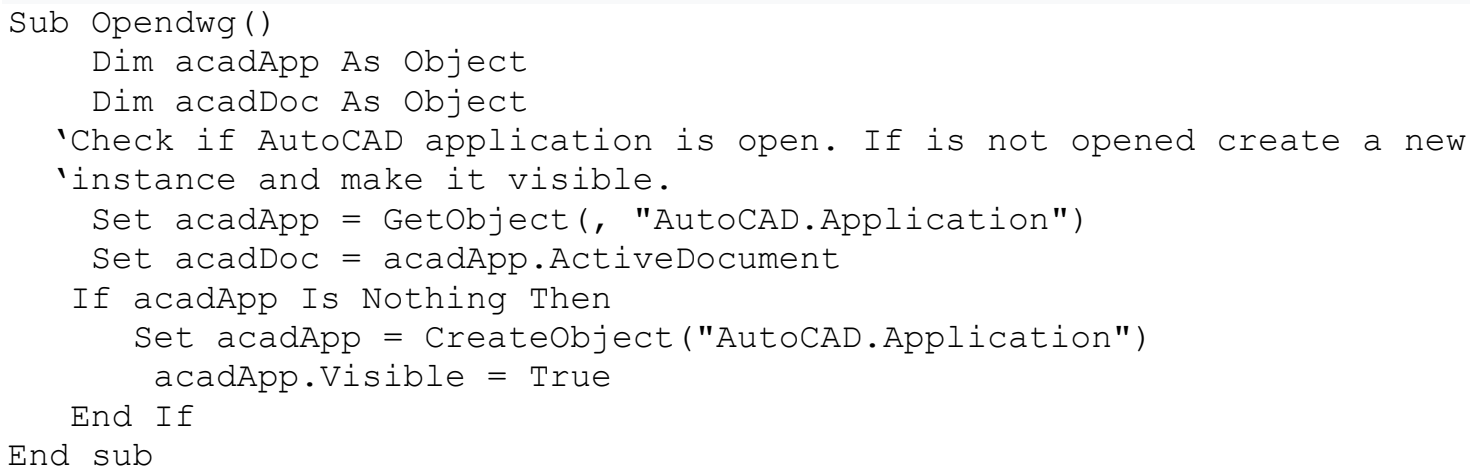

\section{Sending data from Excel to AutoCAD}

The problem is whether you can draw the outline of an object (part) in AutoCad using the coordinates in an Excel file. In other words, we have an Excel file that contains the point coordinates (x, y) and we want to join them by lines or by a polyline, to create the profile of the part in 2D. 


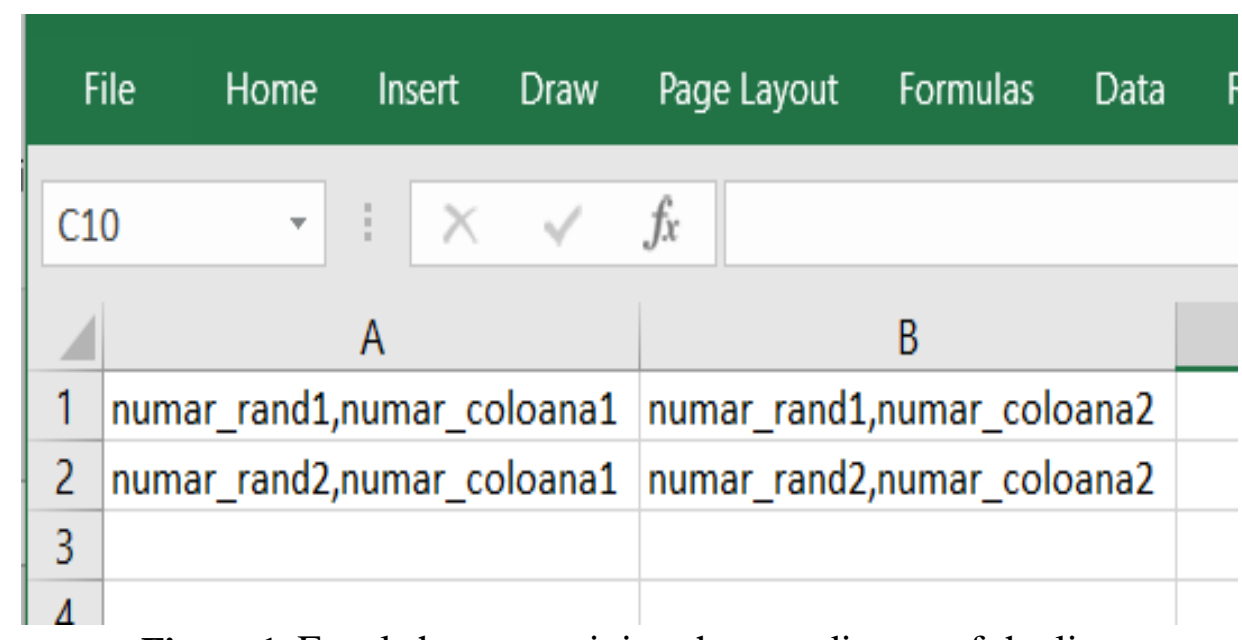

Figure 1. Excel sheet containing the coordinates of the line

The general code for sending data to Autocad, in order to draw a line in ModelSpace, is:

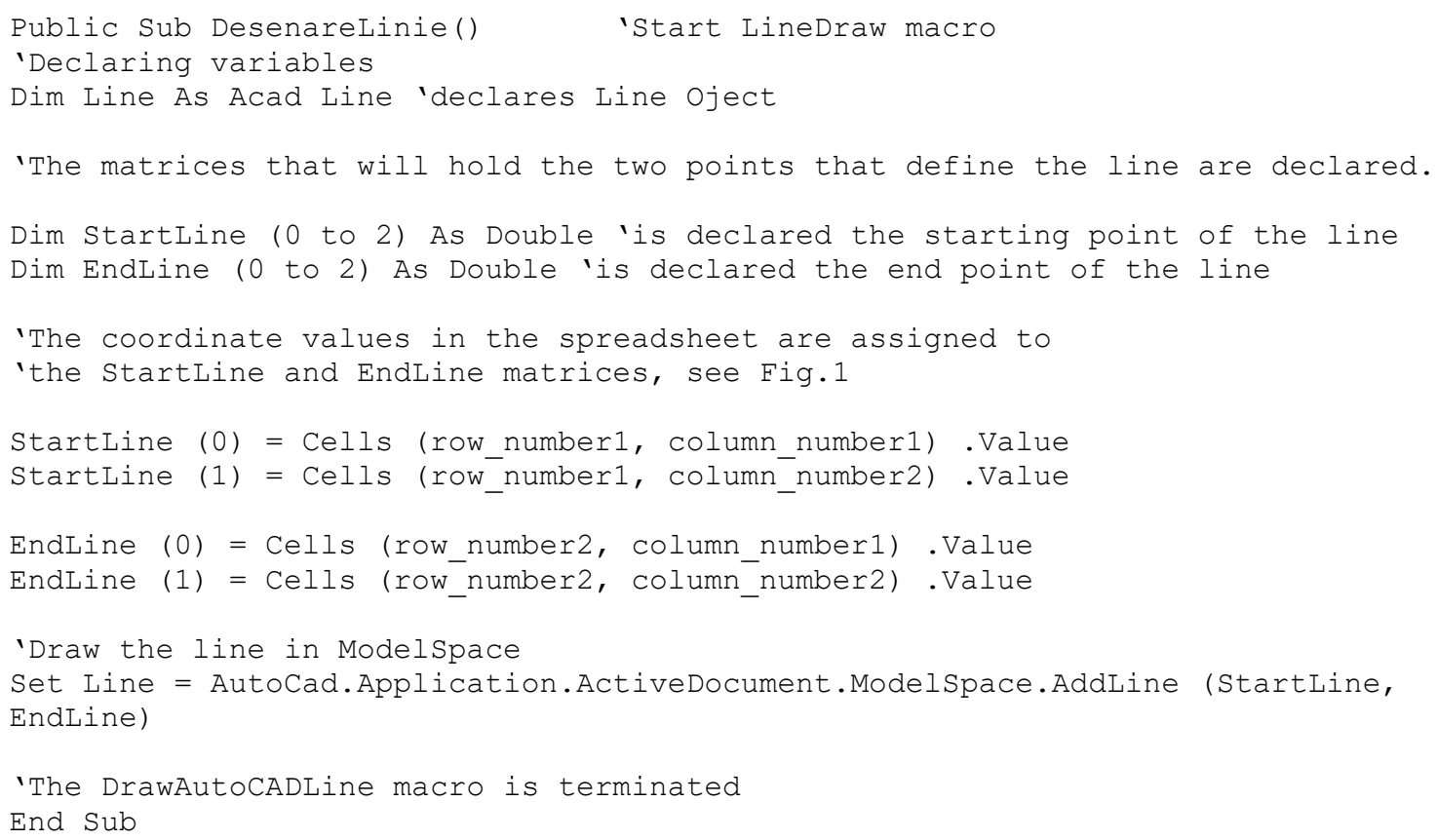

\begin{tabular}{|c|c|c|c|c|c|c|c|c|}
\hline \multicolumn{2}{|c|}{ File } & ome & \multicolumn{2}{|c|}{ Insert } & Draw & Page Layout & \multicolumn{2}{|c|}{ Formulas } \\
\hline $\mathrm{H} 6$ & & 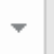 & $\vdots$ & $x$ & $\checkmark$ & $f x$ & & \\
\hline$\triangle$ & A & & $B$ & & $\mathrm{C}$ & $\mathrm{D}$ & $E$ & $\mathrm{~F}$ \\
\hline 1 & & $x$ & & & & & & \\
\hline 2 & Startline & & & & 20 & & & \\
\hline 3 & EndLine & & & & 50 & & & \\
\hline 4 & & & & & & & & \\
\hline 5 & & & & & & & & \\
\hline 6 & & & & & & & & \\
\hline
\end{tabular}

Figure 2. Example of an Excel sheet containing the coordinates of the line 
Example of assigning the coordinates from the spreadsheet of the StartLine and EndLine matrices, (see Fig.2):
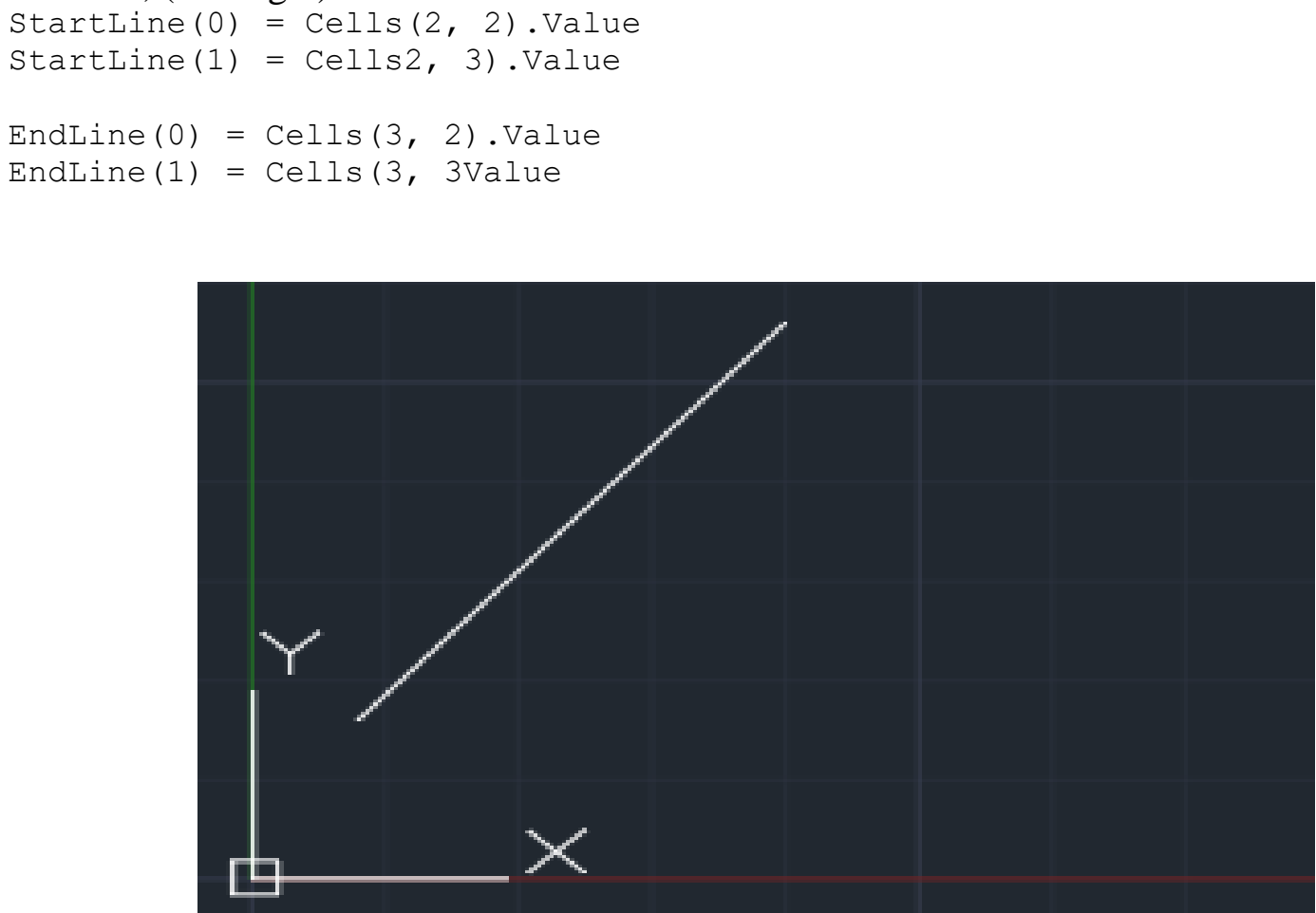

Figure 3. Running Macro DrawingLine ()

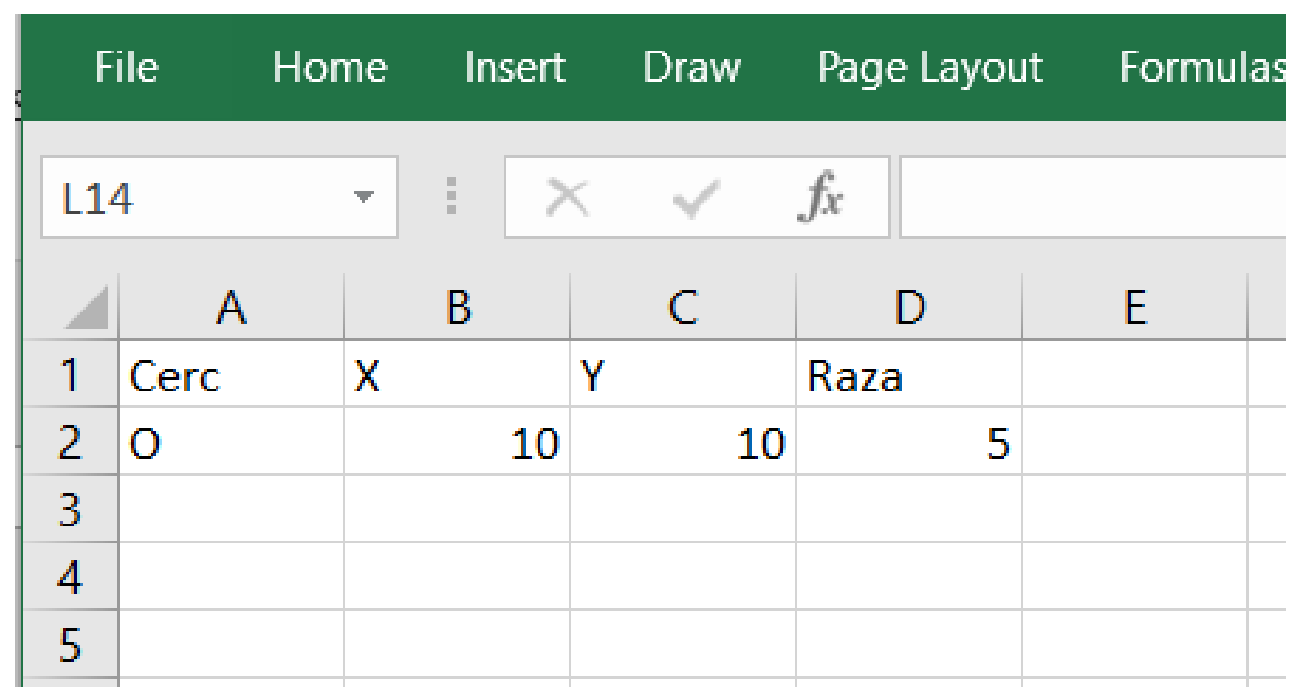

Figure 4. Example of an Excel sheet containing the coordinates of the circle

The general code for sending data to Autocad, in order to draw a circle in ModelSpace, is: Sub DesenareCerc()

'Declare variables

Dim Cerc As AcadCircle 'Circle Object

Dim Centru (0 To 2) As Double 'Center of the circle

Dim Raza AS Double 'Radius of the circle

'Create a circle using data from an Excel sheet

'Assign the coordinate values from the spreadsheet: Radius, Center (see Fig.4) Raza $=$ Cells $(2,4)$. Value 
Centru $(0)=$ Cells $(2,2)$. Value

Centru $(1)=\operatorname{Cells}(2,3)$. Value

'Draw a circle

Set Cerc = Acad.Application.ActiveDocument.Modelspace.AddCircle (Center, Radius)

End Sub

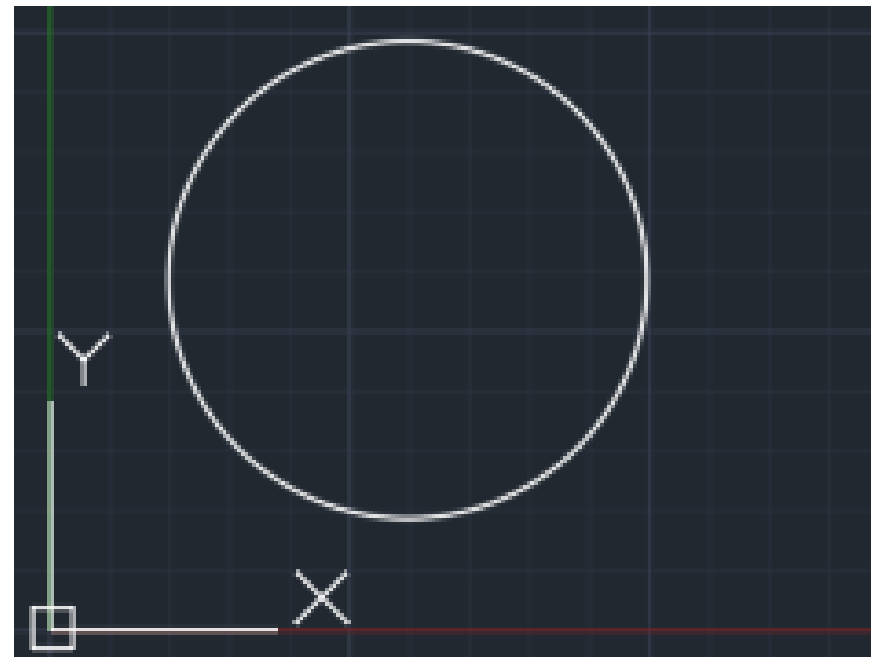

Figure 5. Macro run DesenareCerc()

Proposed example: Let be an Excel sheet with the coordinates of a piece (see Fig. 6). Using a VBA Excel CrearePiesa(), procedure, pass the data from the Excel sheet to Autocad to draw the part.

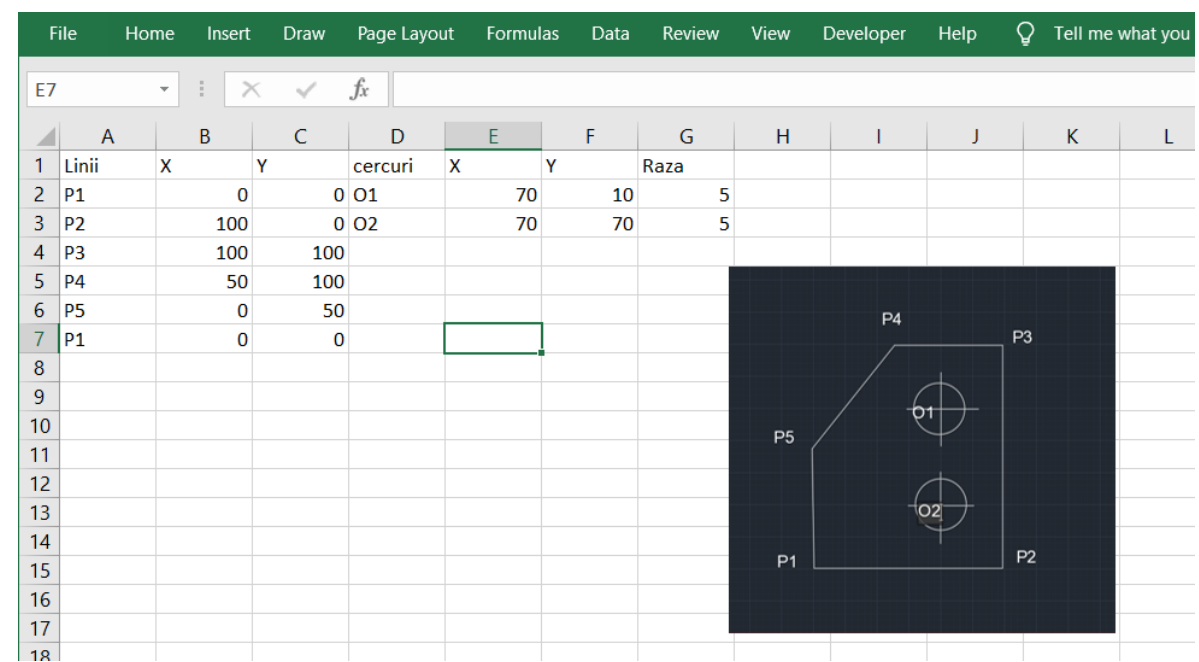

Figure 6. Excel sheet with the coordinates of the piece

Pseudocode of the procedure:

Procedure CrearePiesa()

Line de tip Acad Line

StartPoint, EndPoint de tip Double

Integer Row 'Count the row in Excel

- Variable declaration for circles

Cerc type AcadCircle, Circle object

Centru type Double 'The center of the circle

Raza type Double ' Circle's radius

Coloana type Double intreg 'Count the column in Excel

'For drawing lines

For Rand $=2$ to 7 executes 

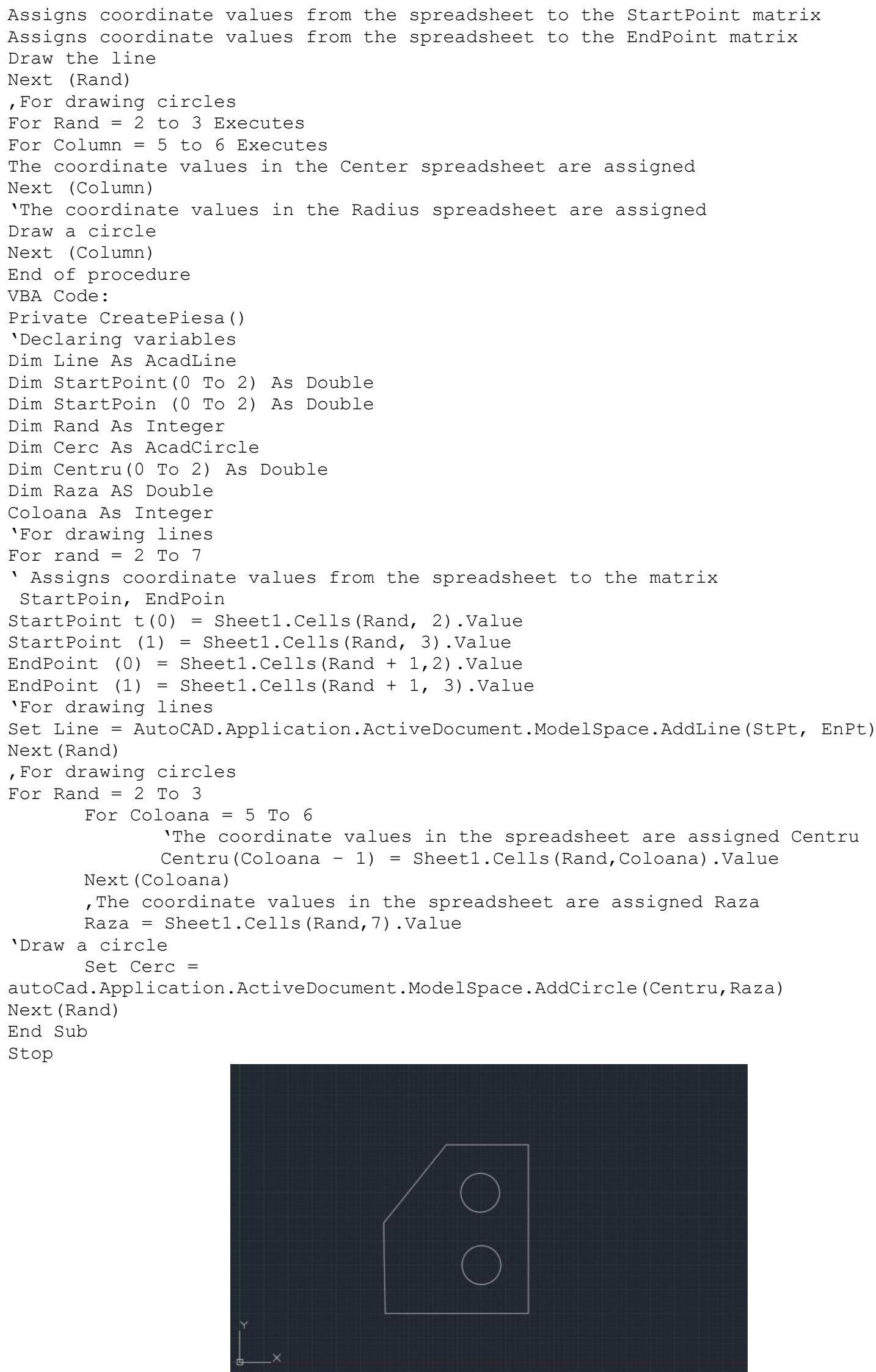

Figure 7. Result after running CreatePieasa macro () 


\section{Conclusions}

Linking Excel to Autocad using VBA makes it easier for engineers and more. By creating applications we can automate some processes, we can draw objects, we can calculate the cost of a product, we can change the attributes of some blocks, in the case of components of a drawing or entities of an Autocad drawing, we can generate a list of materials, we can apply for profiled bars, screws, nuts, standard or standardized objects, etc

\section{References}

[1] AutoCad 2006 VBA A Programmer's Reference, Joe Sutphin, Editura Aprees, 2006

[2] https://vdocuments.mx/autocad-excel-vba-tutorial-558452a84d484.html

[3] https://frfly.wordpress.com/2018/01/28/excel-vba-autocad-basics/

[4] https://drive-cad-with-code.blogspot.com/ 